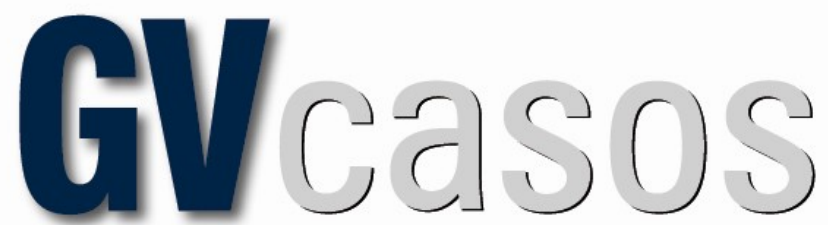

Volume 8

Número 2

$\mathrm{Jul} /$ Dez 2018

Doc. 10

Rev. Bras. de Casos de Ensino em Administração

ISSN 2179-135X

DOI: http://dx.doi.org/10.12660/gvcasosv8n2c10

\title{
QUANTO MAIS SIMPLES, MELHOR: GESTÃO EM UM RESTAURANTE VEGETARIANO
} The simpler, the better: management in a vegetarian restaurant

Aline Mendonça Fraga - alinemf.adm@gmail.com

Universidade Federal do Rio Grande do Sul - Porto Alegre RS, Brasil

VANessa Amaral Prestes - vanessa.amaral.prestes@gmail.com

Universidade Federal do Rio Grande do Sul - Porto Alegre RS, Brasil

Catia Eli Gemelli - catia.gemelli@osorio.ifrs.edu.br

Instituto Federal de Educação, Ciência e Tecnologia do Rio Grandes do Sul - Osório, RS, Brasil

Submissão: 26/07/2018 | Aprovação: 14/09/2018

\begin{abstract}
Resumo
O caso ilustra uma situação real que enfatiza a relação entre o estilo de vida de Ravi, proprietário de um pequeno restaurante vegetariano na cidade de Porto Alegre, e o modelo de gestão adotado no seu negócio. $\mathrm{O}$ acirramento na concorrência com o crescimento da oferta de restaurantes com culinária vegetariana e vegana trouxe novos desafios para a gestão do Manjari. O aumento na rotatividade e a escassez de novos profissionais instigam Ravi a pensar em novas estratégias de gestão de pessoas. Ele deseja aprimorar o seu negócio para clientes e colaboradores, mas sem perder a simplicidade.

Palavras-chave: gestão de pessoas, recrutamento, seleção, retenção, treinamento.
\end{abstract}

\begin{abstract}
The case illustrates a real situation that emphasizes the relationship between the lifestyle of Ravi, owner of a small vegetarian restaurant in the city of Porto Alegre, and the management model adopted in his business. The increase in competition with the growth of restaurants offering vegetarian and vegan cuisine has brought new challenges for the management of Manjari. The increase in turnover and the shortage of new professionals instigate Ravi to think about new people management strategies. He wants to improve his business for customers and employees, but without losing simplicity.
\end{abstract}

Keywords: people management, recruitment, hiring, training.

"Quanto mais simples, melhor"

"Quanto mais simples, melhor" é a filosofia que Ravi mantém em sua vida e também no seu negócio. Proprietário de um restaurante de culinária indiana/vegetariana renomado na cidade de Porto Alegre, ele busca aprimorar o seu negócio para os clientes e colaboradores, mas sempre mantendo a simplicidade.

Ravi, no entanto, entende que precisa de transformações para manter o negócio rentável e competitivo, principalmente no que se refere às suas estratégias de Gestão de Pessoas. Mas nada de mecanizar as relações ou adotar ferramentas de gestão burocratizadas! Melhorar, mas sem complicar... Esse é o desejo de Ravi e o seu desafio! 


\section{A história}

Chileno, com 55 anos de idade, Ravi faz da culinária sua profissão e filosofia de vida. Atua como chefe de cozinha há mais de 20 anos, mas sua formação não foi adquirida em um curso técnico ou de graduação. A sua formação mistura-se com a sua própria história.

No ano de 1981, mudou-se para um mosteiro hindu na cidade de Curitiba/PR, onde permaneceu até o ano de 1990. Assim como todos os moradores do local, ele colaborava com as atividades diárias, tanto religiosas como de alimentação e organização do convívio coletivo. Começou a trabalhar como aprendiz de cozinheiro e, com o tempo, tornou-se o sacerdote responsável pelas oferendas de alimentos, função de grande responsabilidade e que exigia técnica e cuidado. Para realizar essa importante tarefa, recebeu o treinamento de um mestre da cozinha, que lhe passou os ensinamentos de uma culinária milenar e tradicional, de cinco mil anos atrás. Ravi sempre relembra essa etapa da sua formação profissional e pessoal:

- A gente treina, quase um ano, mais de um ano, não pode nem acender o fogo, só olhar, cuidar como eles fazem e aprender. A cozinha do altar é ligada à adoração, ao tempo, é bem mais restrita nos horários, e são muitas oferendas. Eu tive que aprender tudo isso, então essa é a minha formação. Eu aprendi a cozinhar sem provar a comida, pois não pode provar enquanto prepara. Só depois de pronta e oferecida.

Depois de quase 10 anos de vivência e aprendizados no mosteiro, incluindo uma passagem pela Índia, no ano de 1991, Ravi foi convidado para trabalhar na cozinha de um restaurante na cidade de Porto Alegre. Inicialmente sua função era de apenas substituir um funcionário afastado durante uma semana, no entanto sua trajetória profissional no local durou 18 anos.

Ao ser questionado sobre o que o fez para permanecer como funcionário nesse restaurante por tanto tempo, imediatamente respondeu:

- O ambiente de trabalho! Era muito bom, e, além disso, na época, o restaurante era um ponto de encontro do cenário artístico e cultural de Porto Alegre. Era frequentado por músicos, atores, escritores... Eu cozinhava para pessoas como o Caio Fernando Abreu. Além disso, os donos aceitaram que eu adaptasse a cozinha ao meu jeito, sem peixe, sem ovo, ingredientes que eles usavam até então.

Ravi levou para sua profissão os ensinamentos aprendidos no mosteiro, a filosofia hindu e os elementos da cultura indiana e do movimento Hare Krishna, do qual fez parte. A alimentação consciente, prática da ayurveda, foi levada consigo para o trabalho e mantida em sua própria alimentação: não utiliza ovos nem carnes (inclusive peixes e frutos do mar) no preparo dos alimentos. Com o passar do tempo, reuniu uma equipe de trabalho que passou a seguir os mesmos preceitos. Além disso, nessa época, surgiu o questionamento: Por que não abrir um restaurante próprio que disseminasse essa filosofia de vida?

Assim nasceu a ideia que, no ano de 2007, deu origem ao Manjari Restaurante, localizado em uma casa alugada e adaptada na cidade de Porto Alegre. O negócio, inicialmente, contava com uma equipe de 10 funcionários. Atualmente, são oito pessoas contratadas, divididas entre a cozinha e o salão (atendimento aos clientes), além dele próprio, que permanece trabalhando na cozinha e na gestão do local. Nos sábados, domingos e feriados, outros dois garçons trabalham como apoio extra no atendimento ao salão. O Quadro 1 apresenta a relação de funcionários e a descrição das suas principais funções.

Surpreendentemente, grande parte dos clientes regulares do restaurante, segundo Ravi, não é necessariamente vegetariana ou vegana. São pessoas que almoçam quase todos os dias ou comparecem semanalmente e destacam o cardápio variado, a comida saborosa e saudável como principais motivos para a fidelização. Os temperos diferenciados, típicos da culinária indiana, também sobressaem como um ponto forte, contou Ravi.

Ainda que boa parte dos clientes seja onívora (come carne), vegetarianos e veganos são os mais fiéis ao local. Como as refeições podem ser adaptadas de lactovegetarianas (que incluem 
derivados do leite) para veganas, a pedido dos clientes, o Majari recebe ambos os públicos, que têm crescido nos últimos anos. Esses clientes costumam conversar com Ravi, que está sempre presente no local para troca de ideias e de conhecimento. A preocupação com saúde e alterações éticas é destacada pelos novos vegetarianos como principal motivação para a mudança, como destaca Ravi:

- O principal motivo para as pessoas virarem vegetarianas ainda é a saúde. Mas também tem a parte ética e moral de não querer matar um animal, de fazê-lo sofrer só porque tu queres desfrutá-lo. Então, essa é a outra parte de que as pessoas estão se dando conta. O principal motivo que atrai as pessoas ainda é a parte da saúde, mas, depois, o que as mantém como vegetarianas é a parte ética.

O Quadro 2 apresenta informações sobre a cidade de Porto Alegre e ilustra o crescimento do público vegetariano na capital gaúcha. Até o início dos anos 1990, Porto Alegre tinha apenas três restaurantes vegetarianos, o que demonstra o potencial de crescimento que esse mercado representa. Ainda que a carne seja uma expressão cultural com tradição no estado do Rio Grande do Sul, o número de pessoas vegetarianas é significativo, o que justifica o aumento da oferta de opções para esse público. Destaca-se que o primeiro fast-food vegano brasileiro foi inaugurado na capital gaúcha, no ano de 2014.

\section{Da cozinha para a gestão}

- Eu não sou muito bom administrador, sou um cozinheiro, na verdade, mas eu tive a sorte de ter uma boa gerente...

Ravi logo percebeu que seu ponto forte e verdadeira paixão é a cozinha, por isso contratou uma gerente para cuidar da administração do seu negócio. Nutricionista por formação, mas atuando há anos na função de gerente de restaurante, Simone é quem cuida de todas as tarefas administrativas. O cardápio e a cozinha são de responsabilidade de Ravi, com o apoio da chefe de cozinha Tereza, que foi sua colega no monastério, por isso conhece todos os procedimentos e preceitos do restaurante. A chefe trabalha na função desde a inauguração do restaurante.

Por ser sua primeira experiência e por trabalhar com pessoas que considerava mais como amigas do que como funcionárias, Ravi iniciou sua gestão de maneira informal, principalmente no que se referia ao pagamento de salário dos funcionários. Com o crescimento do negócio, viu-se obrigado a formalizar e modificar alguns procedimentos, como a concessão de adiantamentos e de folgas. Essa organização foi realizada por uma contadora contratada para a tarefa, mas causou descontentamento. Acostumada com a informalidade, a equipe demorou a se adaptar às novas regras. Ravi acredita que sua inexperiência como gestor e a própria formação de vida foram fatores que influenciaram essa postura inicial:

- Nesse negócio de ter sido monge, a gente fica meio assim, meio informal, eu fui meio informal no começo, me arrependi, agora já estamos fazendo uma coisa mais organizada, porque não adianta, precisa formalizar para funcionar.

Ravi considera que a busca de apoio em profissionais especializados(as) é o grande segredo para que sua gestão funcione e a sua concentração possa voltar-se à culinária e à conservação do estilo de vida que tanto preza e que se tornou o diferencial do seu restaurante. O ambiente do Majari, marcado por traços da religião hindu e de elementos da cultura indiana, faz refletir tal filosofia de modo tão forte e presente que grande parte da equipe e, também, ex-funcionários e funcionárias passaram a seguir a alimentação vegetariana, os princípios ayurveda e a filosofia hindu.

\section{Dificuldades}

Há nove anos, Ravi adquiriu um imóvel próprio para sediar seu restaurante. O local passou por adaptações, contudo melhorar as condições ambientais na cozinha ainda é um desafio. No verão, a temperatura do local é alta e, muitas vezes, os ventiladores instalados não dão conta de deixar o local com temperatura agradável aos trabalhadores. Apesar dessa dificuldade, o maior desafio para a 
gestão do negócio não são as questões estruturais, mas, sim, aquelas relacionadas à Gestão de Pessoas.

Outrora, o recrutamento de novos membros da equipe era feito por meio de indicação dos próprios funcionários e até dos próprios clientes. Com o passar do tempo, o recrutamento e a seleção tornaram-se um desafio, principalmente para as tarefas de auxiliar de cozinha e de limpeza. Foi necessário contratar uma empresa terceirizada somente para a atividade de limpeza, com o objetivo de sanar o problema constante de recrutamento e seleção de novos profissionais para o desempenho dessa tarefa.

Na cozinha, o desafio é encontrar pessoas que se adaptem aos preceitos seguidos e que aprendam as técnicas e o uso de temperos diferentes dos usualmente utilizados na gastronomia tradicional gaúcha e brasileira. Além disso, nos próprios cursos de formação culinária, a cozinha vegetariana é pouco explorada: a carne é o principal ingrediente, e os demais são complementos dos pratos. Nesse sentido, o desafio ultrapassa uma simples questão de formação e envolve aspectos comportamentais, como destaca Ravi:

- Às vezes, vem gente com formação na área, curso de culinária e tudo, mas chega aqui e não consegue trabalhar bem com nossos temperos ou não se adapta à nossa filosofia.

Os novos membros da equipe contratados para desempenhar funções na copa, caixa e salão são treinados por Ravi e Simone. Já as pessoas contratadas para auxiliarem na cozinha são treinadas por Ravi e Tereza. Os treinamentos sempre contam com o apoio dos funcionários mais antigos, que auxiliam os novatos e oferecem suporte quando surgem dúvidas. Não há um programa de treinamento formalizado, pois Ravi entende que cada pessoa precisa de instruções diferentes, a partir do seu nível de conhecimento sobre a cozinha vegetariana, prática da ayurveda etc. Os pontos mais importantes do treinamento são, justamente, aqueles ligados à filosofia do restaurante.

Trabalhar aos finais de semana é outro fator que dificulta a contratação e também aumenta a rotatividade. $\mathrm{O}$ restaurante abre aos sábados e domingos, dias que concentram maior movimento. Dessa forma, toda a equipe é convocada para trabalhar nesses dias e recebe folga durante a semana. Ravi percebe que isso causa desmotivação, pois muitos dos funcionários que pediram demissão justificaram que haviam encontrado novos empregos que não exigiam dedicação nos finais de semana.

A maior parte dos desligamentos, no entanto, não é por solicitação de funcionários, e, sim, por decisão da gestão do restaurante, em razão da inadequação às exigências do cargo. Segundo Ravi, as funções com maior rotatividade são as de garçom e garçonete:

- É muito difícil conseguir pessoas que consigam trabalhar bem no salão. Tem que ter um mínimo de educação com nossos clientes, cumprimentar, tratar bem... Além disso, tem que cumprir o horário de trabalho. Precisei demitir muitas pessoas porque não chegavam no horário. $\mathrm{O}$ restaurante abria, as pessoas iam chegando, e tinha garçom que ainda não estava no trabalho.

À parte do salário, os(as) funcionários(as) recebem a alimentação no próprio restaurante e todos os direitos legais garantidos pela legislação, como o percentual extra para trabalhar nos finais de semana, parte dos $10 \%$ da taxa de serviço e o vale-transporte. O único benefício oferecido é o plano de saúde, por meio da contratação de um plano empresarial por adesão.

É importante destacar que a equipe possui liberdade para opinar, e o diálogo é valorizado, visto que faz parte da própria filosofia de vida adotada por Ravi. A sua única cobrança, da qual não abre mão, é que eles tenham entusiasmo: entusiasmo!

- Quero que os clientes sempre sejam bem-atendidos. Peço que eles tenham sempre

\section{Desafios}

O número de restaurantes com culinária vegetariana e vegana está crescendo na cidade de Porto Alegre, atendendo ao aumento de demanda por esse tipo de alimentação. Mesmo os 
restaurantes que têm como pratos principais a carne estão oferecendo opções para essa clientela. Segundo o sítio virtual "www.beringela.me", que faz o mapeamento de restaurantes vegetarianos e veganos na cidade, a fim de torná-los mais visíveis e colaborar com a sua permanência, existem 36 restaurantes vegetarianos e veganos registrados no ano de 2018. O crescimento na oferta interfere na concorrência do mercado, diminuindo a clientela dos locais já existentes, mesmo os mais tradicionais.

Nesse cenário, ao mesmo tempo que se amplia a concorrência por clientes, os estabelecimentos passam a competir também pelos profissionais com experiência específica da culinária. Inclusive nas funções que exigem menos experiência, como a de auxiliar de cozinha e de garçom ou garçonete, os locais passam por dificuldades para a atrair e reter pessoas. Com isso, o restaurante de Ravi tem registrado aumento na rotatividade e diminuição na oferta de profissionais para recrutamento. Criar e manter uma equipe motivada e alinhada à filosofia que acompanha a culinária vegetariana e vegana tornou-se um desafio, e novas técnicas para entusiasmar os funcionários se fazem vitais para o futuro do Manjari.

Ravi entende que precisa implantar melhorias nas suas estratégias de Gestão de Pessoas, principalmente no que se refere aos seguintes subsistemas operacionais de recursos humanos: recrutamento e seleção; treinamento; e retenção de pessoas. Diante disso, propõe-se o desafio: Como inovar a Gestão de Pessoas do restaurante sem perder a simplicidade?

Quadro 1. Quadro de funcionários

\begin{tabular}{|c|c|c|}
\hline Cargo & Principais funções & $\begin{array}{c}\mathrm{N}^{0} \text { de funcionários(as) } \\
\text { no cargo }\end{array}$ \\
\hline Gerente & $\begin{array}{l}\text { Planejar, supervisionar e coordenar as } \\
\text { atividades do restaurante. }\end{array}$ & 1 \\
\hline Chefe de cozinha & $\begin{array}{c}\text { Coordenar e supervisionar toda a } \\
\text { atividade da cozinha. }\end{array}$ & 1 \\
\hline Auxiliar de cozinha & $\begin{array}{c}\text { Auxiliar no pré-preparo e processamento } \\
\text { dos alimentos, além de higienização e } \\
\text { organização da cozinha. }\end{array}$ & 2 \\
\hline Garçom & $\begin{array}{l}\text { Atendimento aos clientes no salão: } \\
\text { informar sobre o cardápio e } \\
\text { funcionamento do restaurante, anotar } \\
\text { pedidos, servir e limpar as mesas. }\end{array}$ & $\begin{array}{c}2 \text { fixos } \\
2 \text { intermitentes (finais de } \\
\text { semana e feriados) }\end{array}$ \\
\hline Operador de caixa & $\begin{array}{c}\text { Atendimento ao público externo com } \\
\text { pagamentos e recebimentos de valores, } \\
\text { fechamento de caixa e emissão de notas } \\
\text { fiscais. }\end{array}$ & 1 \\
\hline $\begin{array}{l}\text { Atendente de copa e } \\
\text { cozinha }\end{array}$ & $\begin{array}{l}\text { Atendimento ao público interno, } \\
\text { servindo e distribuindo alimentos e } \\
\text { bebidas. }\end{array}$ & 1 \\
\hline
\end{tabular}


QUANTO MAIS SIMPLES, MELHOR: GESTÃO EM UM RESTAURANTE VEGETARIANO Aline Mendonça Fraga, Vanessa Amaral Prestes, Catia Eli Gemelli

Quadro 2. Dados da cidade de Porto Alegre

\begin{tabular}{|l|c|}
\hline $\begin{array}{l}\text { População total de Porto Alegre segundo o IBGE } \\
(2017)\end{array}$ & 1.484 .942 habitantes \\
\hline $\begin{array}{l}\text { Número de restaurantes vegetarianos registrados no } \\
\text { ano de } 2013\end{array}$ & 36 \\
\hline $\begin{array}{l}\text { Número de restaurantes vegetarianos registrados no } \\
\text { ano de } 2018\end{array}$ & $6 \%$ \\
\hline $\begin{array}{l}\text { Percentual da população que se declarava vegetariana } \\
\text { no ano de } 2012 \text {, de acordo com pesquisa Ibope (2012) }\end{array}$ & $8 \%$ \\
\hline $\begin{array}{l}\text { Percentual da população de regiões metropolitanas que } \\
\text { se declarava vegetariana no ano de } 2018\end{array}$ & \\
\hline
\end{tabular}

Fonte: http://beringela.me/

IBGE (2017) e Ibope (2012). 